Published in final edited form as:

Ann Intern Med. 2018 June 19; 168(12): 866-873. doi:10.7326/M17-2499.

\title{
Projected Cancer Incidence Rates and Burden of Incident Cancer Cases in HIV-Infected Adults in the United States Through 2030
}

\author{
Meredith S. Shiels, PhD, MHS, \\ National Cancer Institute, Rockville, Maryland \\ Jessica Y. Islam, MPH, \\ National Cancer Institute, Rockville, Maryland, and University of North Carolina Gillings School of \\ Global Public Health, Chapel Hill, North Carolina \\ Philip S. Rosenberg, PhD, \\ National Cancer Institute, Rockville, Maryland \\ H. Irene Hall, PhD, MPH, \\ National Center for HIV/AIDS, Viral Hepatitis, STD, and TB Prevention, Centers for Disease \\ Control and Prevention, Atlanta, Georgia \\ Evin Jacobson, PhD, MS, and \\ National Center for HIV/AIDS, Viral Hepatitis, STD, and TB Prevention, Centers for Disease \\ Control and Prevention, Atlanta, Georgia
}

Eric A. Engels, MD, MPH

National Cancer Institute, Rockville, Maryland

\footnotetext{
Requests for Single Reprints: Meredith S. Shiels, PhD, MHS, National Institutes of Health, National Cancer Institute, 9609 Medical Center Drive, Room 6E218, MSC 9767, Bethesda, MD 20892; shielsms@ mail.nih.gov.

Current Author Addresses: Dr. Shiels: 9609 Medical Center Drive, Room 6E218,MSC 9767, Bethesda, MD 20892.

Ms. Islam: 135 Dauer Drive, 2101 McGavran-Greenberg Hall, CB \#7435, Chapel Hill, NC 27599-7435.

Dr. Rosenberg: 9609 Medical Center Drive, Room 7E130, Bethesda, MD 20892.

Dr. Hall: 1600 Clifton Road, Mailstop D-21, Atlanta, GA 30329.

Dr. Jacobson: 1600 Clifton Road, Mailstop E-48, Atlanta, GA 30333.

Dr. Engels: 9609 Medical Center Drive, Room 6E226, MSC 9767, Bethesda, MD 20892.

Author Contributions: Conception and design: M.S. Shiels, P.S. Rosenberg, E.A. Engels.

Analysis and interpretation of the data: M.S. Shiels, J.Y. Islam, P.S. Rosenberg, H.I. Hall, E. Jacobson, E.A. Engels.

Drafting of the article: M.S. Shiels, J.Y. Islam, P.S. Rosenberg, E. Jacobson.

Critical revision of the article for important intellectual content: M.S. Shiels, J.Y. Islam, P.S. Rosenberg, H.I. Hall, E.A. Engels.

Final approval of the article: M.S. Shiels, J.Y. Islam, P.S. Rosenberg, H.I. Hall, E. Jacobson, E.A. Engels.

Provision of study materials or patients: M.S. Shiels.

Statistical expertise: M.S. Shiels, P.S. Rosenberg, E. Jacobson.

Collection and assembly of data: M.S. Shiels, H.I. Hall, E. Jacobson, E.A. Engels.
}

Disclosures: Authors have disclosed no conflicts of interest. Forms can be viewed at www.acponline.org/authors/icmje/

ConflictOfInterestForms.do?msNum=M17-2499.

Disclaimer: The findings, conclusions, and views in this report are those of the authors and do not necessarily represent the official position of the Centers for Disease Control and Prevention, the National Cancer Institute, participating HIV/AIDS or cancer registries, or their contractors.

Presented at the American Association for Cancer Research Annual Meeting, Washington, DC, 1-5 April 2017; at the Society for Epidemiologic Research Annual Meeting, Seattle, Washington, 20-23 June 2017; and as a plenary session at the 16th International Conference on Malignancies in HIV/AIDS, Bethesda, Maryland, 23-24 October 2017.

Reproducible Research Statement: Study protocol: Available from Dr. Shiels (shielsms@mail.nih.gov) Statistical code: Not available Data set: Not available 


\section{Abstract}

Background: Persons living with HIV (PLWH) have an elevated risk for certain types of cancer. With modern antiretroviral therapy, PLWH are aging and cancer rates are changing.

Objective: To project cancer incidence rates and burden (number of new cancer diagnoses) among adult PLWH in the United States through 2030.

Design: Descriptive.

Setting: HIV/AIDS Cancer Match Study to project cancer rates and HIV Optimization and Prevention Economics model to project HIV prevalence.

Participants: HIV-infected adults.

Measurements: Projected cancer rates and burden among HIV-infected adults in the United States by age during 2006 to 2030 for AIDS-defining cancer (ADC; that is, Kaposi sarcoma, nonHodgkin lymphoma, and cervical cancer) and certain types of non-AIDS-defining cancer (NADC). All other cancer types were combined.

Results: The proportion of adult PLWH in the United States who are aged 65 years or older is projected to increase from $8.5 \%$ in 2010 to $21.4 \%$ in 2030 . Age-specific rates are projected to decrease through 2030 across age groups for Kaposi sarcoma, non-Hodgkin lymphoma, cervical cancer, lung cancer, Hodgkin lymphoma and other cancer types combined, and among those aged 65 years or older for colon cancer. Prostate cancer rates are projected to increase. The estimated total cancer burden in PLWH will decrease from 8150 cases in 2010 (2730 of ADC and 5420 of NADC) to 6690 cases in 2030 (720 of ADC and 5980 of NADC). In 2030, prostate cancer ( $n=$ $1590)$ and lung cancer $(n=1030)$ are projected to be the most common cancer types.

Limitation: Projections assume that trends in current cancer incidence rates, HIV transmission, and survival will continue.

Conclusion: The cancer burden among PLWH is projected to shift, with prostate and lung cancer expected to emerge as the most common types by 2030. Cancer will remain an important comorbid condition, and expanded access to HIV therapies and cancer prevention, screening, and treatment is needed.

\section{TOC summary}

Persons living with HIV (PLWH) have a greatly improved life expectancy due to the introduction of potent antiretroviral drug therapies. Projecting future rates and number of incident diagnoses of both AIDS-defining and non-AIDS defining cancer in PLWH is important in order to inform the design of programs for prevention, screening, and treatment.

Mortality among persons living with HIV (PLWH) has been drastically reduced by treatment with effective antiretroviral therapy (ART), which suppresses HIV replication and improves immune function (1). A person newly diagnosed with HIV in North America is expected to live to his or her early 70s with treatment (2). This increased longevity has shifted the age distribution of U.S. PLWH from 27\% aged 50 years or older in 2006 to $45 \%$ in $2014(3,4)$, and the fraction of older PLWH is expected to continue growing. 
Antiretroviral therapy has also reduced the risk for certain types of cancer known to occur in excess among PLWH, particularly AIDS-defining cancer (ADC; that is, Kaposi sarcoma [KS], certain types of non-Hodgkin lymphoma [NHL], and cervical cancer) $(5,6)$. The decrease in ADC rates combined with the growth and aging of the U.S. HIV population has resulted in a shift from predominantly ADC in the 1980s (7) to predominantly non-AIDSdefining cancer (NADC) in 2010 and a net increase in incident cancer diagnoses (that is, cancer burden) over time (8). The most frequent types of NADC in PLWH include those that occur at a higher rate among PLWH (such as anal cancer, liver cancer, oral cavity and pharyngeal cancer, and Hodgkin lymphoma [which are caused by viral co-infections] and lung cancer) and those that are common in the general population (such as prostate, breast, and colon cancer) (8).

The cancer burden among U.S. PLWH will continue to evolve as cancer incidence rates and the size and demographics of the HIV population change over time. We used populationbased data on HIV and cancer to project cancer incidence rates in the adult HIV population and the HIV Optimization and Prevention Economics (HOPE) model to forecast the number of PLWH through 2030. We then calculated projected cancer burden. These results highlight anticipated reductions in cancer burden with continued and expanded access to ART and identify types of cancer expected to predominate in the future, informing public health research and the prioritization of cancer prevention, early detection, and treatment.

\section{Methods}

\section{Cancer Incidence Rate Projections}

Cancer incidence in PLWH was estimated from the National Cancer Institute's HIV/AIDS

Cancer Match Study, a record linkage study of HIV and cancer registries in 9 U.S. regions (www.hivmatch.cancer.gov). This analysis considered the most common cancer types among PLWH: KS; NHL; Hodgkin lymphoma; and cervical, anal, lung, liver, oral cavity and pharyngeal, prostate, breast, and colon cancer (9), classified on the basis of the International Classification of Diseases for Oncology, Third Edition (10). All other cancer sites were analyzed together as "other types of cancer."

We modeled trends in cancer incidence rates during 2000 to 2012 to project rates during 2013 to 2030. Follow-up began on whichever occurred last: 1 January 2000, the beginning of cancer registry coverage, or the first of HIV report date or AIDS diagnosis date. It ended at either death or the end of cancer registry coverage. Cancer incidence rates among adults were estimated in strata defined by calendar year and age group (18 to 24 years, 25 to 34 years, 35 to 44 years, 45 to 64 years, and 65 years or older), and by risk group for KS and anal cancer (men who have sex with men [MSM] and non-MSM) and liver cancer (persons who inject drugs [PWID] and non-PWID). Age groups were combined on the basis of the number of observed cancer cases in each group (Appendix Table 1, available at Annals.org). Children and (for some cancer sites) younger adults were excluded because cancer in these groups was too rare to model. We used joinpoint regression (11) to identify statistically significant changes in the slope of time trends (i.e., joinpoints). We identified 3 cancer incidence trends with significant joinpoints. For NHL, we restricted our analysis to years after the joinpoint (2002 and later). However, because follow-up data were limited for anal 
cancer in MSM (joinpoint, 2009) and liver cancer in PWID (joinpoint, 2005), we used 2000 to 2012 to analyze these cancer sites (Appendix, available at Annals.org).

We used Poisson regression to estimate the annual change in cancer incidence rates during 2000 to 2012. Estimated $\beta$-coefficients and variance-covariance matrixes were then used to project cancer incidence rates and 95\% CIs for 2013 to 2030. Age group was included as a term in the model unless a significant interaction $(P \leq 0.10)$ between age group and calendar year was present, in which case age group-specific models were estimated. If no statistically significant trend was observed during 2000 to 2012, modeled 2012 rates were applied for 2013 to 2030. For cancer types known to be elevated in PLWH, we assumed a priori that future cancer rates would never be lower than those observed in the general population. Therefore, for these cancer types, any projected rate that was lower than the 2013 agespecific rate in the SEER-18 (Surveillance, Epidemiology, and End Results-18) data (12) (used as a proxy for the U.S. general population) was reset to the SEER rate. Likewise, because PLWH have a lower risk for prostate, breast, and colon cancer for unclear reasons $(9,13)$, we assumed that the age-specific rates of these cancer types would never exceed those in SEER-18 (Appendix). Rates standardized by age (and by risk group for KS, anal cancer, and liver cancer) were estimated for 2006 to 2030 by standardizing each year to the 2010 modeled HIV population (see below).

\section{HIV Population Estimates}

The number of PLWH in the United States during 2006 to 2030 was estimated with the dynamic, compartmental HOPE model, which simulates the sexually active population of the United States beginning in 2006 (Appendix) (14, 15). In brief, the population is stratified into 195 subpopulations by transmission group (gay, bisexual, and other MSM [collectively called MSM]; PWID; or heterosexuals); sex (male or female); race/ethnicity (black; Hispanic or Latino; or combined white and other racial/ethnic groups, of which whites comprised 89\%); age group (13 to 17 years, 18 to 24 years, 25 to 34 years, 35 to 44 years, 45 to 64 years, or 65 years or older); male circumcision status (circumcised or uncircumcised); and HIV risk level (low or high), defined for this model on the basis of previously published methods. The force of HIV infection, or the rate at which susceptible persons acquire it, is a function of HIV prevalence among their partners and transmission risk from sexual and needle contacts with infected partners $(16,17)$. The technical report of a previous article based on the HOPE model (15) provides the 2 mixing matrixes that represent the distributions of sexual and needle-sharing partners. The HOPE model assumes continued improvement in HIV care based on an observed trend during 2009 to 2012, resulting in longer survival of PLWH and reduced HIV transmission. Uncertainty estimates for each calendar year were generated (Appendix).

\section{Cancer Burden Projections}

The number of incident cancer diagnoses (that is, cancer burden) per calendar year was estimated by multiplying incidence rates specific to age and risk groups by numbers of PLWH in corresponding strata. Uncertainty estimates were generated by multiplying the lower and upper $95 \%$ CIs from the incidence rates by the minimum and maximum numbers of PLWH, respectively (Appendix). 
We compared the cancer burden estimates in 2030 in 2 scenarios: assuming a flat projection of the 2012 cancer incidence rate and assuming that the age distribution (but not population size) in 2030 remained the same as in 2012. These approaches provide insight into the independent effects that changing cancer incidence rates and age structure of the HIV population have on the estimated burden.

For comparison, we also present the proportion of the total cancer burden contributed by each cancer site among PLWH during 2010 and 2030 and in the general U.S. population in 2010, with data from SEER-18.

\section{Results}

\section{Cancer Incidence Rates Among Adult PLWH, 2000 to 2030}

Between 2000 and 2012, a total of 23907 cases of cancer occurred among 463300 HIVinfected adults in the HIV/AIDS Cancer Match Study. During that time, observed incidence rates decreased significantly $(P<0.05)$ for KS, NHL, cervical cancer, anal cancer (among MSM), lung cancer, Hodgkin lymphoma, and other cancer types across all age groups and for colon cancer among only those aged 65 years or older. Incidence rates of NHL, cervical cancer, and lung cancer are projected to decrease to the general population rates for some age groups (Appendix Table 1 and Appendix Figure 1, available at Annals.org). Prostate cancer rates increased significantly among men aged 35 to 44 years and 45 to 64 years, reaching general population rates, but not among men aged 65 years or older. No significant trends $(P \geq 0.05)$ were observed across age groups for rates of anal cancer among non-MSM, liver cancer among PWID and non-PWID, oral cavity and pharyngeal cancer, and breast cancer, or among those aged 25 to 64 years for rates of colon cancer (Appendix Table 1).

Age-standardized incidence rates are projected to decrease during 2006 to 2030 for 7 of 11 cancer sites. This includes all 3 types of ADC and 4 of 8 types of NADC but excludes breast, oral cavity and pharyngeal, and liver cancer, for which rates are expected to remain stable, and prostate cancer, for which rates will increase (Figure 1, $A$ to $C$ ). We project the largest relative declines (approximately 80\%) in age-standardized incidence rates per 100 000 PLWH for KS (129.8 to 29.0 cases), NHL (184.3 to 36.1 cases), and cervical cancer (61.0 to 10.2 cases).

\section{Estimated Number of Adult PLWH, 2006 to 2030}

The number of adult PLWH in the United States is projected to increase from 1.06 million in 2006 to 1.17 million in 2018 before decreasing to 1.09 million in 2030 (Figure 2). This projected decrease is caused by declines in HIV incidence rates due to reduced transmission resulting from increases in the proportion of PLWH who know they are infected, receive effective treatment, and are virally suppressed (15). Of note, the age distribution of PLWH is expected to shift substantially between 2010 and 2030: The proportion of adult PLWH aged 65 years or older will nearly triple from $8.5 \%$ to $21.4 \%$, and the proportion aged 45 to 64 years will increase from $39.4 \%$ to $47.7 \%$ (Appendix Table 2). The sex and racial/ethnic distributions are expected to remain roughly the same, and the fraction of adult PLWH who are MSM is projected to increase slightly (from $55.4 \%$ in 2010 to $61.0 \%$ in 2030). Appendix 
Table 3 (available at Annals.org) gives the minimum and maximum HIV population estimates for each calendar year.

\section{Estimated Cancer Burden Among Adult PLWH, 2006 to 2030}

In 2010, PLWH had an estimated 8150 cancer cases (uncertainty estimate, 7280 to 9210 cases), including 2730 of ADC (uncertainty estimate, 2440 to 3100 cases) and 5420 of NADC (uncertainty estimate, 4850 to 6120 cases) (Table). The total is expected to decrease to 6690 cases (uncertainty estimate, 4950 to 9060 cases) in 2030, driven by strong decreases in ADC but with modest increases in NADC (Figure 3). When examined by age, 1500 fewer cases are expected among PLWH younger than 45 years and 40 additional cases among PLWH aged 45 years or older in 2030 compared with 2010 (Figure 3).

The composition of the cancer burden is expected to shift substantially over time (Figure 4). In 2010, the most common cancer types were NHL (1490 cases [uncertainty estimate, 1350 to 1660 cases]), KS (1120 cases [uncertainty estimate, 990 to 1290 cases]), and lung cancer ( 830 cases [uncertainty estimate, 750 to 920 cases]). By 2020, prostate cancer is expected be the most common (1340 cases [uncertainty estimate, 1060 to 1660 cases]). In 2030, the most common cancer sites will be prostate (1590 cases [uncertainty estimate, 1240 to 1820 cases]), lung (1030 cases [uncertainty estimate, 940 to 1090 cases]), and liver (480 cases [uncertainty estimate, 360 to 630 cases]). The largest decreases between 2010 and 2030 are estimated to occur for NHL ( -1040 cases) and KS ( -880 cases) and the largest increases for prostate ( +840 cases), lung ( +200 cases), and liver cancer $(+120$ cases). The expected cancer burden in 2030 among PLWH will remain different from the observed burden in the general population in 2010, with a higher fraction of liver cancer, anal cancer, and KS (Appendix Figure 2, available at Annals.org).

\section{Influence of Cancer Incidence Rates and the Aging of the HIV Population on Cancer Burden}

To assess the independent effect of changing incidence rates on cancer burden, we estimated the burden for 2030 using the generally higher 2012 incidence rates (fixing the HIV population demographics to the 2030 projection). The burden estimates produced by the 2012 rates were $43 \%$ higher than those projected in the main analysis, including a $197 \%$ increase in ADC and a 24\% increase in NADC (Figure 5). This pattern held for most cancer types, except for breast, liver, and oral cavity and pharyngeal cancer (that is, types that already had flat incidence projections) and prostate cancer. The largest differences in burden were observed for NHL and KS.

To assess the independent effect of aging of the HIV population, we estimated the 2030 cancer burden using the generally younger age structure of the 2012 population (fixing the cancer incidence rates at the 2030 projections). Compared with the results from the main analysis, the cancer burden in 2030 would be $25 \%$ lower if the 2012 age structure were used. The total number of NADC cases would be $28 \%$ lower, whereas the total number of ADC cases would be 3\% higher. Decreases in burden were seen for most cancer types except for cervical cancer, Hodgkin lymphoma, and KS; prostate and lung cancer had the largest decreases (Figure 5). 


\section{Discussion}

Increased life expectancy among PLWH due to effective ART will result in further aging of the HIV population in the coming years. Concurrently, if recent trends in cancer incidence rates among PLWH continue, the incidence rates of many types of cancer will decrease through 2030; the largest declines are predicted for the 2 most common ADC types, NHL and KS. As a result, we forecast notable shifts in the number of incident cancer diagnoses (that is, cancer burden) among PLWH in the coming decade. The fraction of the cancer burden due to ADC will decrease from one third in 2010 to $11 \%$ in 2030, and the most common cancer types diagnosed among PLWH will shift from NHL and KS in 2010 to prostate and lung cancer in 2030.

Antiretroviral therapy has been the most effective means of reducing cancer burden in PLWH and will continue to be critical in the future. It suppresses HIV replication and reduces immunosuppression among PLWH, improving the immune system's ability to control oncogenic viral infections (18). Because most types of ADC are caused by viral coinfections (that is, human herpesvirus- 8 causes KS, Epstein-Barr virus causes some types of NHL, and human papillomavirus [HPV] causes cervical cancer), ART has been particularly effective at reducing ADC incidence $(5,6,19)$. If progress continues, ADC rates for all ages will continue to decrease, and rates of NHL (in older age groups) and cervical cancer will converge with those of the general population before 2030. Although KS and NHL rates in younger age groups will remain higher than those of the general population, declining rates will lead to a notable decrease in the number of these cancer cases through 2030.

The risks for anal, lung, liver, and oral cavity and pharyngeal cancer and Hodgkin lymphoma are elevated among PLWH compared with the general population $(20,21)$. Increased risk is likely driven by a combination of factors. First, PLWH have a higher burden of certain carcinogenic viruses, such as HPV and hepatitis B and C viruses. In addition, lack of viral control in the setting of immunosuppression increases cancer risk (that is, HPV causes anal cancer and some types of tonsil and oropharyngeal cancer, hepatitis B and C viruses cause liver cancer, and Epstein-Barr virus causes Hodgkin lymphoma). Finally, PLWH have a higher prevalence of some cancer risk factors, most notably cigarette smoking $(18,22)$. Of note, elevated risk for lung cancer is not entirely explained by smoking, and immune suppression, chronic lung inflammation, and pulmonary infections may contribute (23-25). Rates of prostate, breast, and colon cancer are actually lower in PLWH in some studies (9, 21).

Between 2000 and 2012, we observed stable or decreasing incidence rates for most types of NADC, except prostate cancer among men aged 35 to 64 years. These trends are generally consistent with those reported in other recent studies $(5,26,27)$. Furthermore, the risks for anal, lung, and liver cancer and Hodgkin lymphoma in U.S. PLWH have declined relative to those in the general population, supporting a role of ART in decreasing risk for these types of cancer (9). Of note, we project that rates of lung cancer will no longer be elevated among PLWH by 2030. Although lung cancer rates have declined significantly, we caution that our projection of a continued decline may not be realistic if the prevalence of smoking does not decrease substantially among PLWH (22). 
Quantifying both incidence rates and burden is important. Rates describe cancer risk among PLWH, whereas burden captures total number of diagnoses. Changes in incidence rates, population age structure, and population size all influence cancer burden. By holding the incidence rates or age structure constant on the basis of 2012 estimates in secondary analyses, we could assess how changes over time contributed to the projections in our main analyses. Decreasing incidence rates most notably affected the decreasing burden of KS, NHL, and cervical cancer. In contrast, the aging of U.S. PLWH resulted in a projected increase for many cancer types, most notably prostate and lung cancer. Although the cancer burden is projected to evolve, it will continue to differ from that in the general population, with a higher fraction of KS, liver cancer, and anal cancer.

The main strengths of this analysis were the data sources, which included high-quality data on cancer incidence in nearly 500000 PLWH and U.S. HIV population estimates from the HOPE model developed by the Centers for Disease Control and Prevention. Our results should be interpreted under the assumption that trends in current cancer incidence, HIV transmission, and survival will continue through 2030, which we largely attribute to improvements in and wider use of ART. Of note, our analysis cannot account for any unexpected changes in HIV or cancer incidence. For example, interventions that have been recently introduced or may expand in the coming years could reduce future cancer risk and burden in PLWH (such as treatment of hepatitis $\mathrm{C}$ virus infection and screening for anal cancer). In contrast, unforeseen changes that reduce access to treatment of HIV infection (such as reductions in health insurance coverage) or increase HIV incidence (such as outbreaks due to increases in injection drug use) would increase the cancer burden among PLWH.

The main limitation is the uncertainty in the input parameters of the HOPE model, although modeled estimates closely matched HIV surveillance estimates for 2014 (28). For example, the latest 2014 estimates from the Centers for Disease Control and Prevention for persons aged 13 to 64 years were 1107700 cases for overall HIV prevalence and 37600 cases for overall HIV incidence (28), and the model predictions were 1042140 and 35761 cases, respectively, suggesting some predictive validity. We did uncertainty analyses by varying the calibrated parameters, and those results indicated robustness in prevalence estimates across potential calibration sets. We have attempted to quantify the uncertainty around our cancer burden estimates by combining information on the uncertainties in rate and population projections. In addition, power was limited for several strata, which may have resulted in trends being modeled as flat projections.

Although the number of cancer cases diagnosed among PLWH is projected to decrease, cancer will remain an important comorbid condition, and continued prevention efforts are needed. Increased access to effective ART will be critical in reducing future cancer burden in PLWH, and current recommendations advocate treatment of all PLWH, regardless of CD4 count (29). Interventions focused on smoking cessation and treatment of hepatitis B and C virus infections could reduce the future burden of lung and liver cancer. Vaccination for HPV has been found to be safe and immunogenic in PLWH (30), and a clinical trial is currently evaluating vaccination in HIV-infected MSM for the prevention of HPV infection and anal intraepithelial neoplasia (ClinicalTrials.gov: NCT01209325). 
Future research and public health programs should also focus on early detection and treatment of cancer among PLWH. Some screen-detectable types (such as breast, lung, and cervical cancer) are more frequently diagnosed at advanced stages among PLWH, perhaps reflecting delayed diagnosis (31). Specific cervical cancer screening guidelines should be followed for HIV-infected women (32). For other types of cancer, screening strategies in PLWH receiving ART should reflect the same consideration of benefits, harms, and costs as in the general population. Of note, an ongoing clinical trial is addressing anal Papinocolau testing and treatment of precancerous lesions among PLWH (ClinicalTrials.gov: NCT02135419), and more research is needed on screening for lung cancer (low-dose computed tomography). Finally, cancer treatment and survival differ between PLWH and the general population, which emphasizes the need to incorporate PLWH into clinical trials and guidelines for cancer treatment (33-35).

In conclusion, we have shown that the number of incident cancer diagnoses (that is, cancer burden) among PLWH will shift substantially through 2030. The incidence rates of most cancer types will likely remain stable or decrease, with the largest declines for NHL and KS. In 2030, prostate and lung cancer are projected to be the most common types, followed by liver and anal cancer. Although the total burden of cancer among PLWH is expected to decrease by $18 \%$, cancer will remain an important comorbid condition, and tailored public health programs focused on cancer prevention, screening, and treatment in PLWH are needed.

\section{Supplementary Material}

Refer to Web version on PubMed Central for supplementary material.

\section{Acknowledgment:}

The authors thank individuals at the following state HIV/AIDS and cancer registries for their support and assistance: Colorado, Connecticut, Georgia, Maryland, Michigan, New Jersey, New York, Puerto Rico, and Texas. They also thank Timothy McNeel at Information Management Services for programming support.

Financial Support: In part by the Intramural Research Program of the National Cancer Institute. The following cancer registries were supported by the SEER Program of the National Cancer Institute: Connecticut (HHSN261201300019I) and New Jersey (HHSN261201300021I; N01-PC-2013-00021). The following cancer registries were supported by the National Program of Cancer Registries of the Centers for Disease Control and Prevention: Colorado (NU58DP006347-01), Georgia (5U58DP003875-01), Maryland (5NU58DP003919-05-00), Michigan (17NU58DP006334), New Jersey (NU58/DP003931-05-00), New York (U58/DP003879), and Texas (1NU58DP006308). The New Jersey State Cancer Registry was also supported by the state of New Jersey, the Maryland Cancer Registry was also supported by the state of Maryland and the Maryland Cigarette Restitution Fund, and the New York State Cancer Registry was also supported by the state of New York. The following HIV registries were supported by the National HIV Surveillance System of the Centers for Disease Control and Prevention HIV Incidence and Case Surveillance Branch: Colorado (NU62PS003960), Connecticut (5U62PS001005-05), Michigan (U62PS004011-02), and New Jersey (U62PS004001-2).

Role of the Funding Source

This study was funded by the Intramural Research Program of the National Cancer Institute. The funder approved a final version of the manuscript before submission but had no role in the design, conduct, or analysis of the study.

Primary Funding Source: National Cancer Institute. 


\section{Appendix:: Additional Details on Methods HIV/AIDS Cancer Match Contributing Registries}

The HIV/AIDS Cancer Match Study is a record linkage study of HIV and cancer registries in the United States (www.hivmatch.cancer.gov). Data from 8 U.S. states (Colorado, Connecticut, Georgia, Maryland, Michigan, New Jersey, New York, and Texas) and Puerto Rico were included in this analysis.

\section{Joinpoint Analysis and Assessment of Heterogeneity by Registry}

Joinpoint regression (11) was used to identify the presence of statistically significant changes in the slope of time trends in crude cancer incidence rates in each age and risk group stratum, and if a significant change was present, calendar years before the joinpoint were excluded from all analyses for that cancer site. Joinpoints were detected in 2002 for NHL among persons aged 35 to 44 years, in 2009 for anal cancer among MSM aged 45 years or older, and in 2005 for liver cancer among PWID aged 65 years or older. Models for NHL were restricted to 2002 and later. Restricting anal and liver cancer models to start in 2009 and 2005, respectively, resulted in too few cases; therefore, the full time period (2000 to 2012) was used in these 2 projections. Of note, the joinpoint trends in the most recent period were not statistically significant for either of these cancer sites. In addition, data from 2000 were excluded from Hodgkin lymphoma models because the rate in that year was extremely high.

For each cancer type, heterogeneity by registry was assessed by including an interaction term between registry and calendar year in the Poisson model. Significant heterogeneity was observed only for NHL and the other combined cancer category. After the registries with the most extreme trends (that is, Maryland for NHL and New Jersey for other types of cancer combined) were excluded, no notable differences in projected incidence rates were observed, so all registries were retained in the main analysis.

\section{Comparison of Modeled and Projected Rates With General Population Rates}

For types of cancer known to be more prevalent in HIV-infected people (KS; NHL; cervical, anal, lung, liver, and oral cavity and pharyngeal cancer; and Hodgkin lymphoma [9]), we assumed a priori that future cancer rates would never be lower than rates observed in the general population. Therefore, any projected rate that was lower than the age-specific rate observed for the U.S. general population, based on data from 18 cancer registries in SEER-18 in 2013 (12), was reset to the SEER rate with an upper confidence limit estimated from the Poisson model and a lower confidence limit estimated from SEER data. If the modeled upper confidence limit was lower than the SEER estimate, the SEER upper confidence limit was used. Likewise, because PLWH have a deficit of prostate, breast, and colon cancer $(9,13)$, we assumed that the age-specific rates of these cancer types would never exceed those in SEER-18. 


\section{HOPE Model}

The number of PLWH in the United States during 2006 to 2030 was estimated with the dynamic, compartmental HOPE model, which simulates the sexually active U.S. population beginning in $2006(14,15)$. The population is stratified into 195 subpopulations by transmission group (gay, bisexual, and other MSM [collectively referred to as MSM]; PWID; or heterosexuals); sex (male or female); race/ethnicity (black; Hispanic or Latino; or combined white and other racial/ethnic groups, of which whites comprised 89\%); age group (13 to 17 years, 18 to 24 years, 25 to 34 years, 35 to 44 years, 45 to 64 years, or 65 years or older); male circumcision status (circumcised or uncircumcised); and HIV risk level (low or high), as defined for this model on the basis of previously published methods $(16,17)$. The force of HIV infection, or the rate at which susceptible persons acquire HIV infection, is a function of HIV prevalence among their partners and transmission risk from sexual and needle contacts with HIV-infected partners.

The total population (PLWH and susceptible persons) transitions among the 25 compartments, which are defined by disease progression and continuum-of-care stage, and moves into (at age 13 years) and out of the model via aging and death. The model uses differential equations to represent the progression of the HIV-uninfected and HIV-infected populations between compartments. Differential equations in the model are solved using MATLAB software (MathWorks). Additional model details, including definitions of all subpopulations and compartments and descriptions of differential equations; force-ofinfection calculations; inputs and sources; calibration; validation; and other methods, assumptions, and specifications, are published in a full technical report on the HOPE model $(14,15)$. This model assumes that no new infections occur among or are caused by persons older than 65 years. The HOPE model has been shown to closely match published HIV surveillance estimates. For example, the latest 2014 estimates from the Centers for Disease Control and Prevention for persons aged 13 to 64 years were 1107700 cases for overall HIV prevalence and 37600 cases for overall HIV incidence (28), and the model predictions were 1042140 and 35761 cases, respectively.

To consider the uncertainty of the HIV prevalence for 2006 to 2030 due to the values of the parameters, we ran the HOPE model using 10 additional sets of values for those inputs that, like the set used in the base-case analysis, approximated the targeted surveillance measures. To generate each of the 10 sets, we went through a calibration process, which was also used to generate the base-case inputs. The process that was applied to calibrate the model is outlined in sections 11.1.1 to 11.1.4 of the published technical report (15). We report the range of the HIV population estimates across those runs. 


\section{Appendix Table 1.}

Description of Joinpoint Analyses and Modeling Decisions, by Cancer Site and Age Group

Variable

Cases, $n \quad$ Significant Joinpoint (Year)

642

$18-34$ y

$35-44$ y

$\geq 45 \mathrm{y}$

Non-MSM

$18-34 \mathrm{y}$

$35-44 y$

$\approx 45 \mathrm{y}$

$\mathrm{NHL}^{\dagger}$

$18-24$ y

25-34 y

$35-44$ y

45-64 y

$\checkmark 65 \mathrm{y}$

Cervical cancer ${ }^{t}$

25-34 y

35-44 y

$\geq 45 \mathrm{y}$

Non-AIDS-defining cancer

Lung cancer $t+$

35-44 y

45-64 y

$265 \mathrm{y}$

Prostate cancer ${ }^{t \neq}$

35-44 y

45-64 y
278

194

420

420

86

529

1660

2403

168

75

252

209

1857

360

52

1116
Annual

Percent

Change ( $P$

Value)

No

No

No

No

No

No

No

Yes (2002)

No

No

No

No

No

No

No

No

No

No
$-5.0(P<$

$0.001)$

$-5.2(P<$

$0.001)$

$-8.0(P$

0.001)

$\begin{array}{cc}-5.2(P=0.01) & \text { No } \\ -8.8(P< & \text { No } \\ 0.001) & \\ -11.3(P< & \text { No } \\ 0.001) & \end{array}$

$-11.1(P$ $0.001)$

$-5.1(P<$ $0.001)$

$-6.2(P<$ $0.001)$

$-9.0(P<$ $0.001)$

$-12.7(P<\quad$ Yes $(2014-2030)$ $0.001)$

$\begin{array}{cc}-8.7(P< & \text { Yes }(2030) \\ 0.001) & \\ -8.7(P< & \text { Yes }(2027-2030) \\ 0.001) & \\ -8.7(P< & \text { Yes }(2025-2030) \\ 0.001) & \end{array}$
$0.001)$

$\begin{array}{cc}-9.1(P< & \text { Yes }(2025-2030) \\ 0.001) & \\ -5.6(P< & \text { Yes }(2020-2030) \\ 0.001) & \\ -7.9(P< & \text { Yes }(2011-2030) \\ 0.001) & \end{array}$

$8.7(P=0.050) \quad$ Yes $(2002-2030)$

$3.5(P<0.001) \quad$ Yes $(2024-2030)$ 


\begin{tabular}{|c|c|c|c|c|}
\hline Variable & Cases, $n$ & Significant Joinpoint (Year) & $\begin{array}{c}\text { Annual } \\
\text { Percent } \\
\text { Change }(P \\
\text { Value })\end{array}$ & $\begin{array}{c}\text { Estimate } \\
\text { Replaced with } \\
\text { SEER 2013 Rate } \\
\text { (Years) }\end{array}$ \\
\hline $265 \mathrm{y}$ & 381 & No & $1.2(P=0.45)$ & No \\
\hline \multicolumn{5}{|l|}{ Anal cancer } \\
\hline \multicolumn{5}{|l|}{$\mathrm{MSM}^{\neq}$} \\
\hline $25-34$ y & 58 & No & $\begin{array}{c}-2.7(P= \\
0.005)\end{array}$ & No \\
\hline $35-44$ y & 330 & No & $\begin{array}{c}-2.7(P= \\
0.005)\end{array}$ & No \\
\hline$\geq 45 \mathrm{y}$ & 537 & Yes $(2009)^{\mathcal{\xi}}$ & $\begin{array}{c}-2.7(P= \\
0.005)\end{array}$ & No \\
\hline \multicolumn{5}{|l|}{ Non-MSM } \\
\hline $25-34$ y & 26 & No & $1.4(P=0.32)$ & No \\
\hline $35-44$ y & 158 & No & $1.4(P=0.32)$ & No \\
\hline$\geq 45 \mathrm{y}$ & 333 & No & $1.4(P=0.32)$ & No \\
\hline \multicolumn{5}{|l|}{ Liver cancer } \\
\hline \multicolumn{5}{|l|}{ PWID ${ }^{t}$} \\
\hline $35-44$ y & 38 & No & $0.8(P=0.51)$ & No \\
\hline $45-64$ y & 577 & No & $0.8(P=0.51)$ & No \\
\hline $265 \mathrm{y}$ & 48 & Yes $(2005)^{\mathcal{S}}$ & $0.8(P=0.51)$ & No \\
\hline \multicolumn{5}{|l|}{ Non-PWID ${ }^{t}$} \\
\hline $35-44$ y & 73 & No & $-1.4(P=0.92)$ & No \\
\hline $45-64$ y & 350 & No & $-1.4(P=0.92)$ & No \\
\hline $265 \mathrm{y}$ & 49 & No & $-1.4(P=0.92)$ & No \\
\hline \multicolumn{5}{|l|}{ Hodgkin lymphoma/l } \\
\hline $18-34$ y & 155 & No & $\begin{array}{c}-4.4(P< \\
0.001)\end{array}$ & No \\
\hline $35-44$ y & 324 & No & $\begin{array}{c}-4.4(P< \\
0.001)\end{array}$ & No \\
\hline$\geq 45 \mathrm{y}$ & 440 & No & $\begin{array}{c}-4.4(P< \\
0.001)\end{array}$ & No \\
\hline \multicolumn{5}{|c|}{ Oral cavity/pharyngeal cancer $t$} \\
\hline $35-44$ y & 105 & No & $\begin{array}{c}-1.5(P= \\
0.175)\end{array}$ & No \\
\hline $45-64$ y & 555 & No & $\begin{array}{c}-1.5(P= \\
0.175)\end{array}$ & No \\
\hline $265 \mathrm{y}$ & 59 & No & $\begin{array}{c}-1.5(P= \\
0.175)\end{array}$ & No \\
\hline \multicolumn{5}{|l|}{ Breast cancer ${ }^{t}$} \\
\hline $25-44$ y & 206 & No & $-1.4(P=0.24)$ & No \\
\hline $45-64$ y & 436 & No & $-1.4(P=0.24)$ & No \\
\hline $265 \mathrm{y}$ & 48 & No & $-1.4(P=0.24)$ & No \\
\hline \multicolumn{5}{|l|}{ Colon cancer ${ }^{\dagger t}$} \\
\hline $25-44$ y & 58 & No & $-4.7(P=0.22)$ & No \\
\hline $45-64$ y & 325 & No & $0.01(P=0.99)$ & No \\
\hline $265 \mathrm{y}$ & 117 & No & $\begin{array}{c}-6.0(P= \\
0.028)\end{array}$ & No \\
\hline
\end{tabular}

Ann Intern Med. Author manuscript; available in PMC 2019 January 11. 
Variable

Cases, $n \quad$ Significant Joinpoint (Year)

Annual
Percent
Change $(\boldsymbol{P}$
Value)

Estimate

Replaced with

SEER 2013 Rate

Value) (Years)

All other cancer types ${ }^{\dagger}$

$\begin{array}{lcccc}18-34 \text { y } & 269 & \text { No } & -5.3(P= & \text { No } \\ & & & 0.002) & \\ 35-44 \text { y } & 1019 & \text { No } & -3.1(P= & \text { No } \\ & & & 0.001) & \\ 45-64 \text { y } & 3379 & \text { No } & -2.0(P< & \text { No } \\ & & & 0.001) & \text { No } \\ 265 \mathrm{y} & 579 & \text { No } & -3.4(P= & 0.008)\end{array}$

MSM = men who have sex with men; NHL = non-Hodgkin lymphoma; PLWH = persons living with HIV; PWID = persons who inject drugs; SEER = Surveillance, Epidemiology, and End Results.

* For types of cancer known to be elevated in PLWH, we assumed a priori that future cancer rates would never be lower than rates observed in the general population. Therefore, any projected rate that was lower than the 2013 age-specific rate in SEER-18 data (as a proxy for the U.S. general population) was reset to the SEER rate. Likewise, because PLWH have a lower risk for prostate, breast, and colon cancer for unclear reasons, we assumed that the age-specific rates of these types of cancer would never exceed those in SEER-18.

${ }^{\dagger}$ Time trends differed significantly across age groups, so trends were projected separately for each age group.

${ }^{*}$ The cancer incidence rates in the youngest age group(s) were assumed to be 0 because of the limited number of reported cases of cervical cancer $(n=1)$, anal cancer in MSM $(n=2)$, anal cancer in non-MSM $(n=0)$, lung cancer $(n=10)$, liver cancer in PWID $(n=0)$, liver cancer in non-PWID $(n=2)$, oral cavity/pharyngeal cancer $(n=7)$, prostate cancer $(n=2)$, breast cancer $(n=2)$, and colon cancer $(n=0)$.

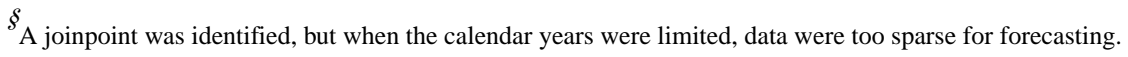
"2000 excluded because of extreme estimates.

Appendix Table 2.

Characteristics of Modeled Adult U.S. HIV Population in 2010, 2020, and 2030*

\begin{tabular}{|c|c|c|c|}
\hline Characteristic & $2010(n=1127669)$ & $2020(n=1161947)$ & $2030(n=1091827)$ \\
\hline \multicolumn{4}{|l|}{ Sex } \\
\hline Male & $846197(75.0)$ & 879868 (75.7) & 838770 (76.8) \\
\hline Female & $281472(25.0)$ & 282079 (24.3) & $253057(23.2)$ \\
\hline \multicolumn{4}{|l|}{ Age group } \\
\hline $18-24$ y & $73130(6.5)$ & $40260(3.5)$ & $21550(2.0)$ \\
\hline $25-34$ y & $212100(18.8)$ & $157330(13.5)$ & $111310(10.2)$ \\
\hline $35-44$ y & $301590(26.7)$ & 254290 (21.9) & $204400(18.7)$ \\
\hline $45-64$ y & $444710(39.4)$ & $520050(44.8)$ & $520470(47.7)$ \\
\hline $265 \mathrm{y}$ & $96139(8.5)$ & 190017 (16.4) & $234097(21.4)$ \\
\hline \multicolumn{4}{|l|}{ Race/ethnicity } \\
\hline Non-Hispanic black & $481535(42.7)$ & $472273(40.6)$ & $419535(38.4)$ \\
\hline Hispanic & 218971 (19.4) & $228199(19.6)$ & 216506 (19.8) \\
\hline Non-Hispanic white/other & $427163(37.9)$ & 461475 (39.7) & $455786(41.7)$ \\
\hline \multicolumn{4}{|l|}{ Risk group } \\
\hline MSM & $624456(55.4)$ & $677332(58.3)$ & $665471(61.0)$ \\
\hline PWID & $193630(17.2)$ & $174103(15.0)$ & $148579(13.6)$ \\
\hline Heterosexual & 309583 (27.5) & 310512 (26.7) & 277777 (25.4) \\
\hline
\end{tabular}


*Values are numbers (percentages).

MSM = men who have sex with men; PWID = persons who inject drugs.

\section{Appendix Table 3.}

Minimum and Maximum Estimates for Adult U.S. HIV Population, by Calendar Year

\begin{tabular}{|c|c|c|c|}
\hline Year & Estimated PLWH, $n$ & Minimum Estimate, $n$ & Maximum Estimate, $n$ \\
\hline 2006 & 1063089 & 1058806 & 1063091 \\
\hline 2007 & 1083294 & 1080005 & 1085508 \\
\hline 2008 & 1100540 & 1098408 & 1107386 \\
\hline 2009 & 1115194 & 1114485 & 1127652 \\
\hline 2010 & 1127669 & 1122937 & 1143608 \\
\hline 2011 & 1138033 & 1135849 & 1154345 \\
\hline 2012 & 1146495 & 1142227 & 1164294 \\
\hline 2013 & 1152985 & 1145083 & 1164667 \\
\hline 2014 & 1157701 & 1150285 & 1170579 \\
\hline 2015 & 1160646 & 1150527 & 1174673 \\
\hline 2016 & 1163729 & 1146365 & 1178523 \\
\hline 2017 & 1165314 & 1141017 & 1181120 \\
\hline 2018 & 1165445 & 1134735 & 1182647 \\
\hline 2019 & 1164345 & 1127537 & 1183059 \\
\hline 2020 & 1161947 & 1119647 & 1182577 \\
\hline 2021 & 1158499 & 1111107 & 1181218 \\
\hline 2022 & 1154081 & 1102013 & 1179068 \\
\hline 2023 & 1148743 & 1092395 & 1176197 \\
\hline 2024 & 1142497 & 1082290 & 1172599 \\
\hline 2025 & 1135609 & 1071792 & 1168422 \\
\hline 2026 & 1127914 & 1060843 & 1163570 \\
\hline 2027 & 1119687 & 1049509 & 1158147 \\
\hline 2028 & 1110830 & 1037915 & 1152268 \\
\hline 2029 & 1101618 & 1025998 & 1145881 \\
\hline 2030 & 1091827 & 1013812 & 1139042 \\
\hline
\end{tabular}

PLWH = persons living with HIV.

\section{References}

1. Ray M, Logan R, Sterne JA, Hernández-Díaz S, Robins JM, Sabin C, et al.; HIV-CAUSAL Collaboration. The effect of combined antiretroviral therapy on the overall mortality of HIVinfected individuals. AIDS. 2010;24:123-37. [PMID: ] doi:10.1097/QAD.0b013e3283324283 [PubMed: 19770621]

2. Samji H, Cescon A, Hogg RS, Modur SP, Althoff KN, Buchacz K, et al.; North American AIDS Cohort Collaboration on Research and Design (NA-ACCORD) of IeDEA. Closing the gap: increases in life expectancy among treated HIV-positive individuals in the United States and Canada. PLoS One. 2013;8:e81355 [PMID: ] doi:10.1371/journal.pone.0081355 [PubMed: 24367482]

3. Centers for Disease Control and Prevention. HIV/AIDS Surveillance Report, 2007. Vol.19 Atlanta: Centers for Disease Control and Prevention; 2009.

4. Centers for Disease Control and Prevention. HIV/AIDS Surveillance Report, 2015. Vol. 27 Atlanta: Centers for Disease Control and Prevention; 2016. 
5. Park LS, Tate JP, Sigel K, Rimland D, Crothers K, Gibert C, et al. Time trends in cancer incidence in persons living with HIV/AIDS in the antiretroviral therapy era: 1997-2012. AIDS. 2016;30:1795806. [PMID: ] doi:10.1097/QAD.0000000000001112 [PubMed: 27064994]

6. Robbins HA, Shiels MS, Pfeiffer RM, Engels EA. Epidemiologic contributions to recent cancer trends among HIV-infected people in the United States. AIDS. 2014;28:881-90. [PMID: ] doi: 10.1097/QAD.0000000000000163 [PubMed: 24300545]

7. Shiels MS, Pfeiffer RM, Gail MH, Hall HI, Li J, Chaturvedi AK, et al. Cancer burden in the HIVinfected population in the United States. J Natl Cancer Inst. 2011;103:753-62. [PMID: ] doi: 10.1093/jnci/djr076 [PubMed: 21483021]

8. Robbins HA, Pfeiffer RM, Shiels MS, Li J, Hall HI, Engels EA. Excess cancers among HIVinfected people in the United States. J Natl Cancer Inst. 2015;107 [PMID: ] doi:10.1093/jnci/dju503 [PubMed: 25663691]

9. Hernández-Ramírez RU, Shiels MS, Dubrow R, Engels EA. Cancer risk in HIV-infected people in the USA from 1996 to 2012: a population-based, registry-linkage study. Lancet HIV. 2017;4:e495504. [PMID: ] doi:10.1016/S2352-3018(17)30125-X [PubMed: 28803888]

10. World Health Organization. International Classification of Diseases for Oncology. 3rd ed. Geneva: World Health Organization; 2000.

11. Kim HJ, Fay MP, Feuer EJ, Midthune DN. Permutation tests for joinpoint regression with applications to cancer rates. Stat Med. 2000;19:335-51. [PMID: ] [PubMed: 10649300]

12. Surveillence, Epidemiology and End Results (SEER) Program (www.seer.cancer.gov) SEER*Stat Database Incidence - SEER 18 Regs Research Data + Hurricane Katrina Impacted Louisiana Cases, Nov 2015 Sub (2000-2013) <Katrina/Rita Population Adjustment> - Linked To County Attributes - Total U.S., 1969-2014 Counties., Vol.: National Cancer Institute, DCCPS, Surveillance Research Program, Surveillance Systems Branch, released April 2016, based on the November 2015 submission; 2016.

13. Coghill AE, Engels EA, Schymura MJ, Mahale P, Shiels MS. Risk of breast, prostate, and colorectal cancer diagnoses among HIV-infected individuals in the United States. J Natl Cancer Inst. 2018 [PMID: ] doi:10.1093/jnci/djy010 [PubMed: 29529223]

14. O'Leary A, DiNenno E, Honeycutt A, Allaire B, Neuwahl S, Hicks K, et al. Contribution of anal sex to HIV prevalence among heterosexuals: a modeling analysis. AIDS Behav. 2017;21:2895903. [PMID: ] doi:10.1007/s10461-016-1635-z [PubMed: 28058564]

15. Uzun Jacobson E, Hicks KA, Tucker EL, Farnham PG, Sansom SL. Effects of reaching national goals on HIV incidence, by race and ethnicity, in the United States. J Public Health Manag Pract. 2017 [PMID: ] doi:10.1097/PHH.0000000000000717 [PubMed: 29283955]

16. Dinenno EA, Oster AM, Sionean C, Denning P, Lansky A. Piloting a system for behavioral surveillance among heterosexuals at increased risk of HIV in the United States. Open AIDS J. 2012;6:169-76. [PMID: ] doi:10.2174/1874613601206010169 [PubMed: 23049666]

17. Sorensen SW, Sansom SL, Brooks JT, Marks G, Begier EM, Buchacz K, et al. A mathematical model of comprehensive test-and-treat services and HIV incidence among men who have sex with men in the United States. PLoS One. 2012;7:e29098 [PMID: ] doi:10.1371/journal.pone.0029098 [PubMed: 22347994]

18. Shiels MS, Engels EA. Evolving epidemiology of HIV-associated malignancies. Curr Opin HIV AIDS. 2017;12:6-11. [PMID: ] [PubMed: 27749369]

19. Engels EA, Pfeiffer RM, Goedert JJ, Virgo P, McNeel TS, Scoppa SM, et al.; HIV/AIDS Cancer Match Study. Trends in cancer risk among people with AIDS in the United States 1980-2002. AIDS. 2006;20:1645-54. [PMID: ] [PubMed: 16868446]

20. Shiels MS, Cole SR, Kirk GD, Poole C. A meta-analysis of the incidence of non-AIDS cancers in HIV-infected individuals. J Acquir Immune Defic Syndr. 2009;52:611-22. [PMID: ] doi:10.1097/ QAI.0b013e3181b327ca [PubMed: 19770804]

21. Grulich AE, van Leeuwen MT, Falster MO, Vajdic CM. Incidence of cancers in people with HIV/ AIDS compared with immunosuppressed transplant recipients: a meta-analysis. Lancet. 2007;370:59-67. [PMID: ] [PubMed: 17617273] 
22. Park LS, Hernández-Ramírez RU, Silverberg MJ, Crothers K, Dubrow R. Prevalence of non-HIV cancer risk factors in persons living with HIV/AIDS: a meta-analysis. AIDS. 2016;30:273-91. [PMID: ] doi:10.1097/QAD.0000000000000922 [PubMed: 26691548]

23. Shiels MS, Cole SR, Mehta SH, Kirk GD. Lung cancer incidence and mortality among HIVinfected and HIV-uninfected injection drug users. J Acquir Immune Defic Syndr. 2010;55:510-5. [PMID: ] doi:10.1097/QAI.0b013e3181f53783 [PubMed: 20838223]

24. Sigel K, Wisnivesky J, Gordon K, Dubrow R, Justice A, Brown ST, et al. HIV as an independent risk factor for incident lung cancer. AIDS. 2012;26:1017-25. [PMID: ] doi:10.1097/QAD. 0b013e328352d1ad [PubMed: 22382152]

25. Sigel K, Wisnivesky J, Crothers K, Gordon K, Brown ST, Rimland D, et al. Immunological and infectious risk factors for lung cancer in US veterans with HIV: a longitudinal cohort study. Lancet HIV. 2017;4:e67-73. [PMID: ] doi:10.1016/S2352-3018(16)30215-6 [PubMed: 27916584]

26. Worm SW, Bower M, Reiss P, Bonnet F, Law M, Fätkenheuer G, et al.; D:A:D Study Group. NonAIDS defining cancers in the D:A:D Study — time trends and predictors of survival: a cohort study. BMC Infect Dis. 2013;13:471 [PMID: ] doi:10.1186/1471-2334-13-471 [PubMed: 24106926]

27. Hleyhel M, Hleyhel M, Bouvier AM, Belot A, Tattevin P, Pacanowski J, et al.; Cancer Risk Group of the French Hospital Database on HIV (FHDH-ANRS CO4). Risk of non-AIDS-defining cancers among HIV-1-infected individuals in France between 1997 and 2009: results from a French cohort. AIDS. 2014;28:2109-18. [PMID: ] doi:10.1097/QAD.0000000000000382 [PubMed: 25265077]

28. Singh S, Song R, Johnson AS, McCray E, Hall I. HIV incidence, prevalence and undiagnosed infections in men who have sex with men [Abstract]. Presented at Conference on Retroviruses and Opportunistic Infections, Seattle, Washington, 13-16 22017 Abstract no. 30.

29. Panel on Antiretroviral Guidelines for Adults and Adolescents; Department of Health and Human Services. Guidelines for the Use of Antiretroviral Agents in HIV-1-Infected Adults and Adolescents. Washington, DC: Department of Health and Human Services; 2015.

30. Wilkin T, Lee JY, Lensing SY, Stier EA, Goldstone SE, Berry JM, et al. Safety and immunogenicity of the quadrivalent human papillomavirus vaccine in $\mathrm{HIV}$-1-infected men. J Infect Dis. 2010;202:1246-53. [PMID: ] doi:10.1086/656320 [PubMed: 20812850]

31. Shiels MS, Copeland G, Goodman MT, Harrell J, Lynch CF, Pawlish K, et al. Cancer stage at diagnosis in patients infected with the human immunodeficiency virus and transplant recipients. Cancer. 2015;121:2063-71. [PMID: ] doi:10.1002/cncr.29324 [PubMed: 25739496]

32. Panel on Opportunistic Infections in HIV-Infected Adults and Adolescents. Guidelines for the prevention and treatment of opportunistic infections in HIV-infected adults and adolescents: recommendations from the Centers for Disease Control and Prevention, the National Institutes of Health, and the HIV Medicine Association of the Infectious Diseases Society of America. 2016 Accessed at https://aidsinfo.nih.gov/contentfiles/lvguidelines/adult_oi.pdf on

33. Suneja G, Shiels MS, Angulo R, Copeland GE, Gonsalves L, Hakenewerth AM, et al. Cancer treatment disparities in HIV-infected individuals in the United States. J Clin Oncol. 2014;32:234450. [PMID: ] doi:10.1200/JCO.2013.54.8644 [PubMed: 24982448]

34. Suneja G, Lin CC, Simard EP, Han X, Engels EA, Jemal A. Disparities in cancer treatment among patients infected with the human immunodeficiency virus. Cancer. 2016;122:2399-407. [PMID: ] doi:10.1002/cncr.30052 [PubMed: 27187086]

35. Coghill AE, Shiels MS, Suneja G, Engels EA. Elevated cancer-specific mortality among HIVinfected patients in the United States. J Clin Oncol. 2015;33:2376-83. [PMID: ] doi:10.1200/JCO. 2014.59.5967 [PubMed: 26077242] 
A.

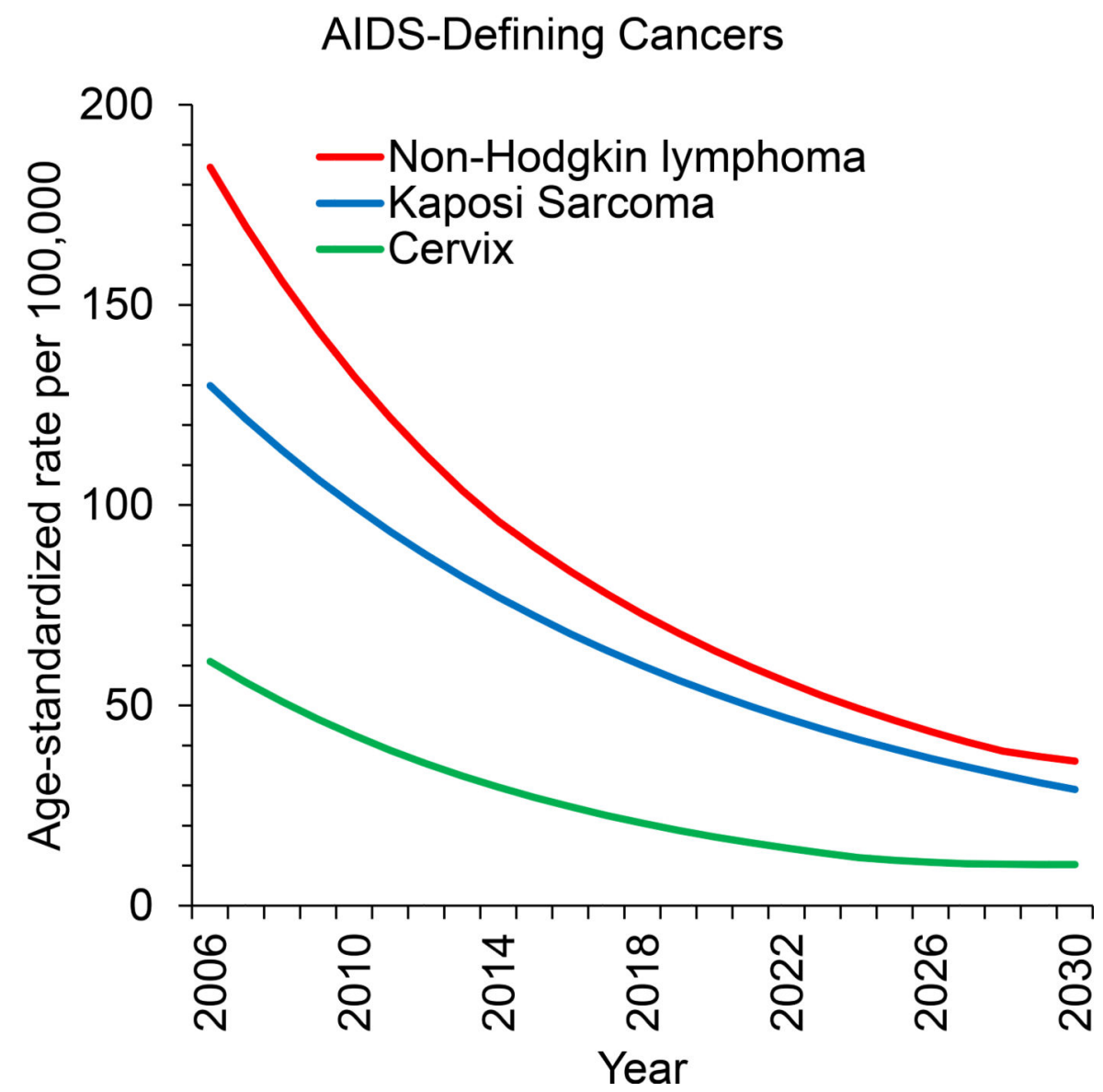


B.

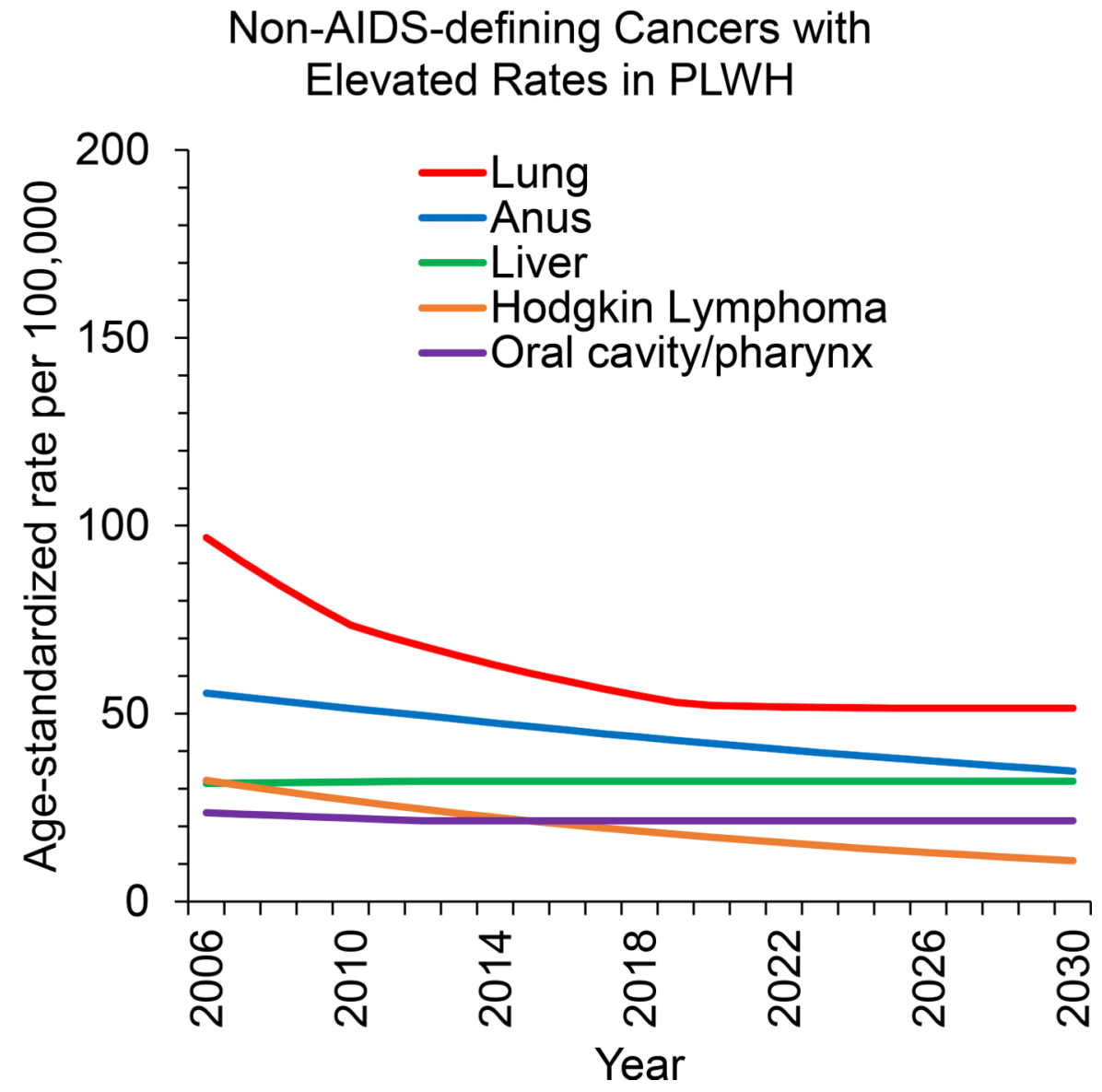


C.

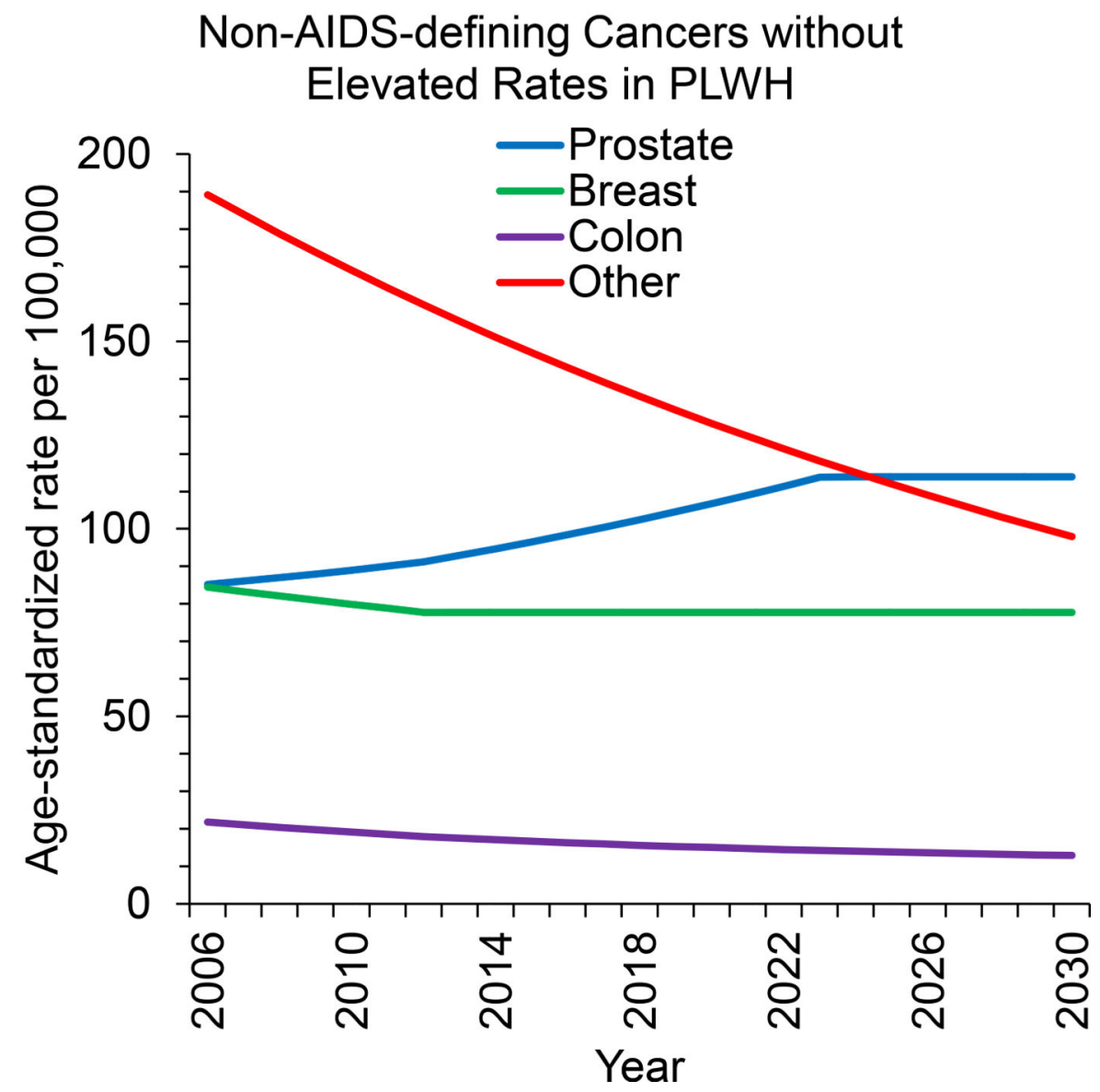

Figure 1. Age-standardized cancer rates for U.S. adults with HIV.

Rates were standardized to the 2010 U.S. HIV population by age group. Rates for cervical and breast cancer were restricted to women, and rates for prostate cancer were restricted to men. $\mathrm{ADC}=\mathrm{AIDS}$-defining cancer; $\mathrm{NADC}=$ non-AIDS-defining cancer; $\mathrm{PLWH}=$ persons living with HIV. 
U.S. Adult HIV Population, 2006-2030

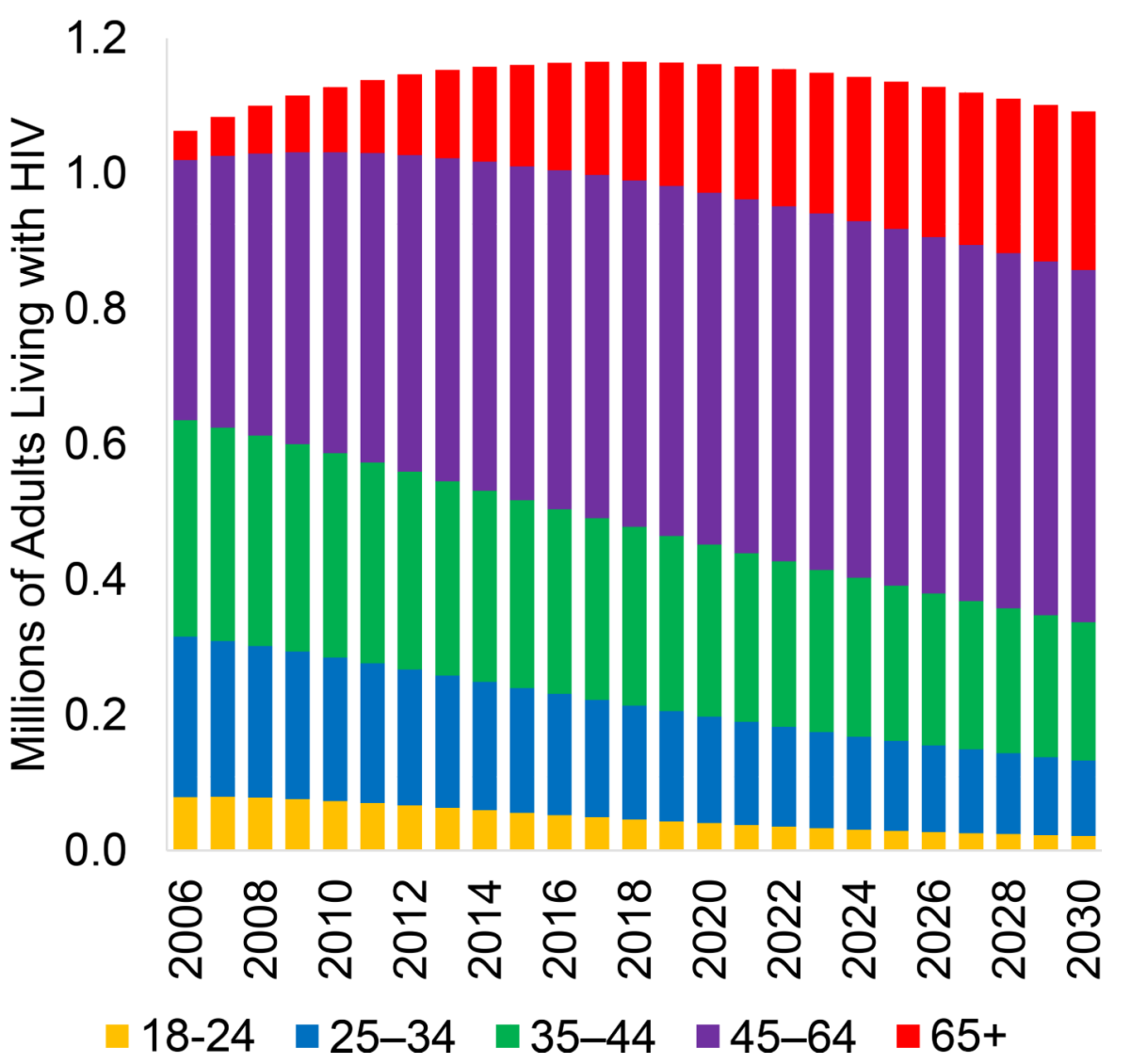

Figure 2. Estimated number of adults living with HIV in the United States during 2006-2030, by age group.

Age groups were 18-24 y, 25-34 y, 35-44 y, 45-64 y, and $265 \mathrm{y}$. 


\section{AIDS-defining and non-AIDS-defining Cancer Burden in U.S. HIV Population by Age}

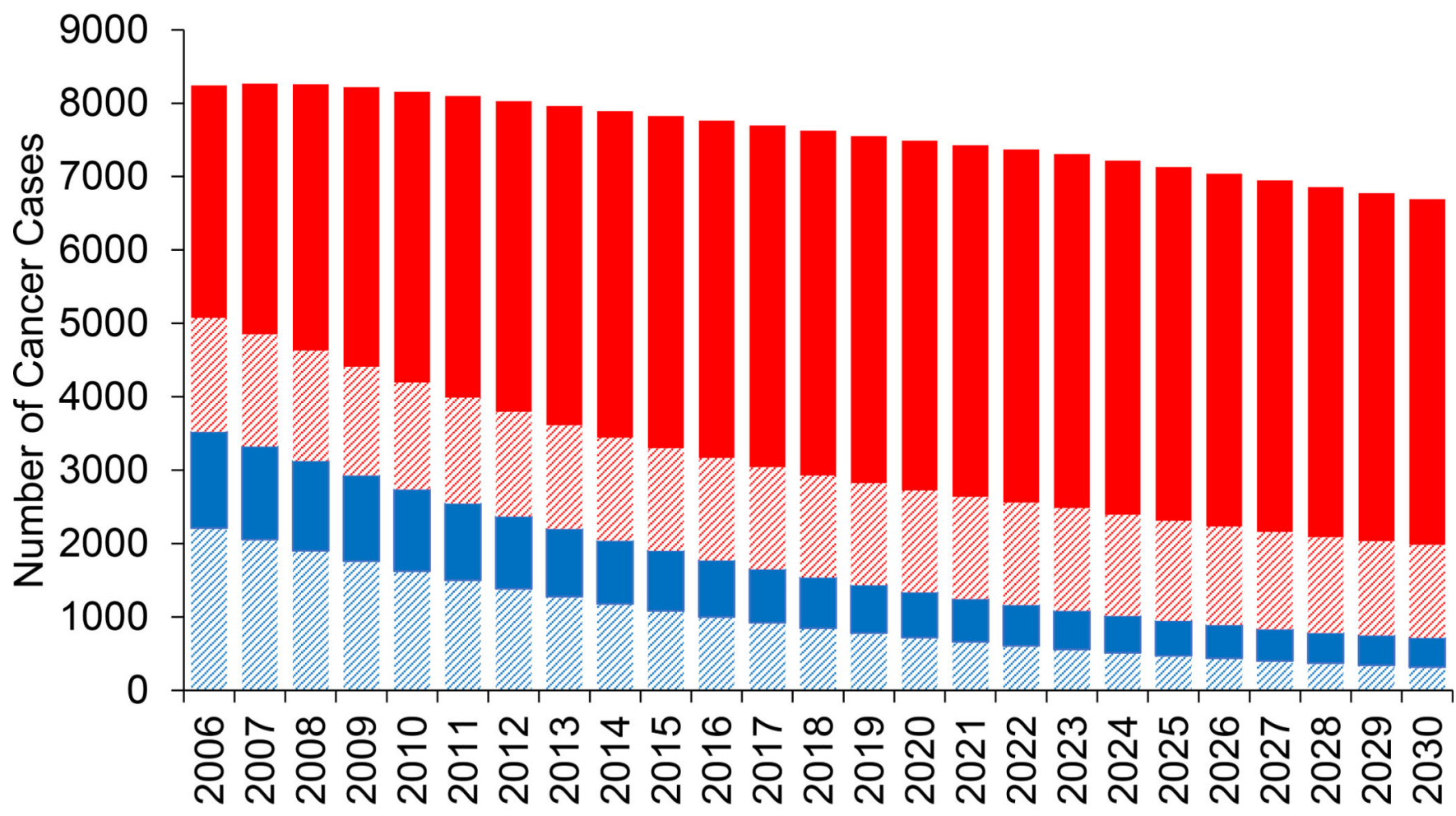

\% ADCs, $<45$ year-olds $\square$ ADCs, $\geq 45$ year-olds \% NADCs, $<45$ year-olds $\square$ NADCs, $\geq 45$ year-olds

Figure 3. Estimated number of incident diagnoses of ADC and NADC in adults living with HIV in the United States during 2006-2030, stratified by age.

Black segments represent ADC, green segments represent NADC, dark bars represent cancer cases among persons aged $\geq 45 \mathrm{y}$, and light bars represent cancer cases among those aged $<45 \mathrm{y} . \mathrm{ADC}=\mathrm{AIDS}-$ defining cancer; NADC $=$ non-AIDS-defining cancer. 


\section{Cancer Burden in U.S. HIV Population}

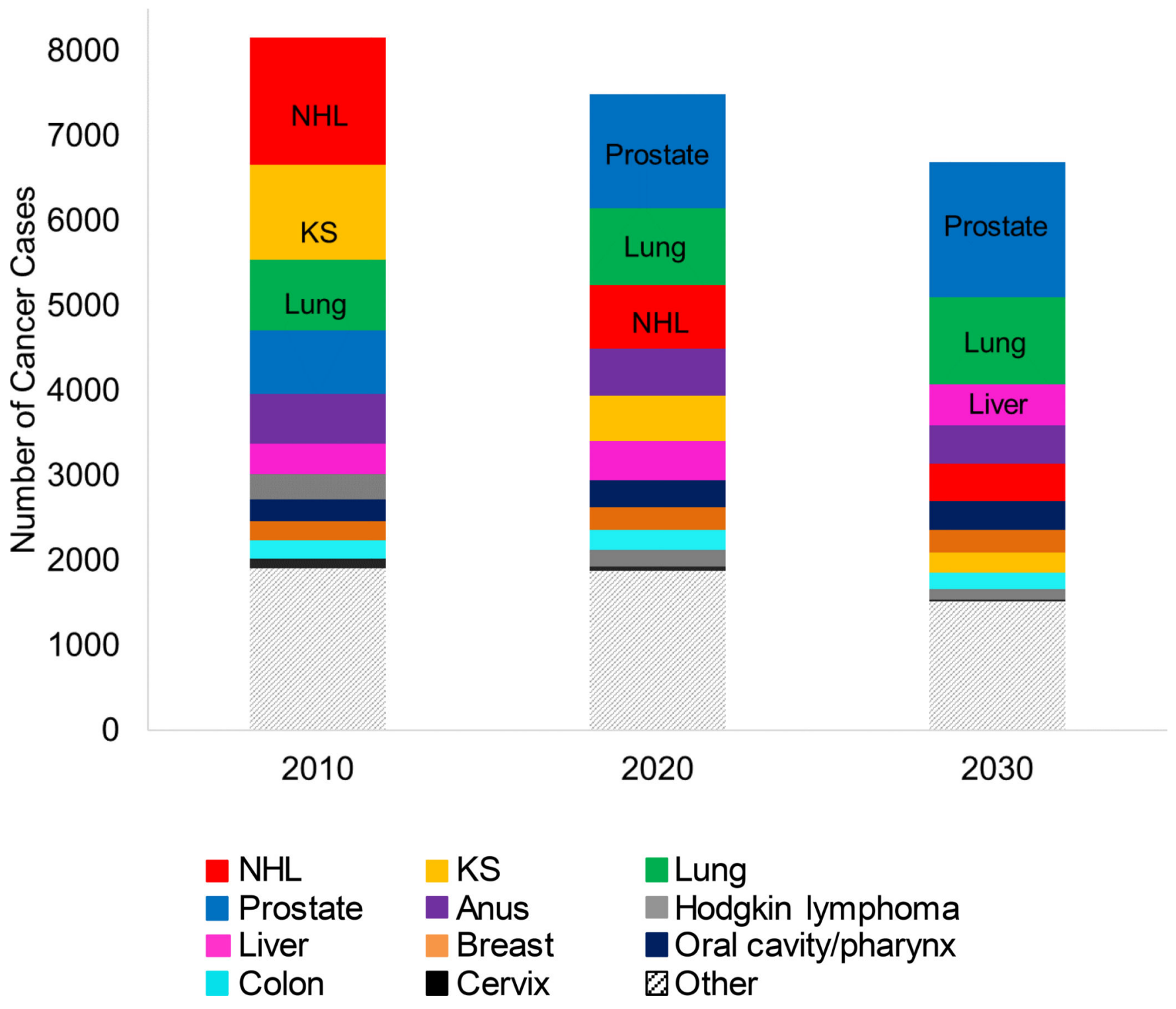

Figure 4. Estimated cancer burden (incident cancer diagnoses) among adults living with HIV in the United States, by cancer type, in 2010, 2020, and 2030.

$\mathrm{KS}=$ Kaposi sarcoma; NHL = non-Hodgkin lymphoma. 


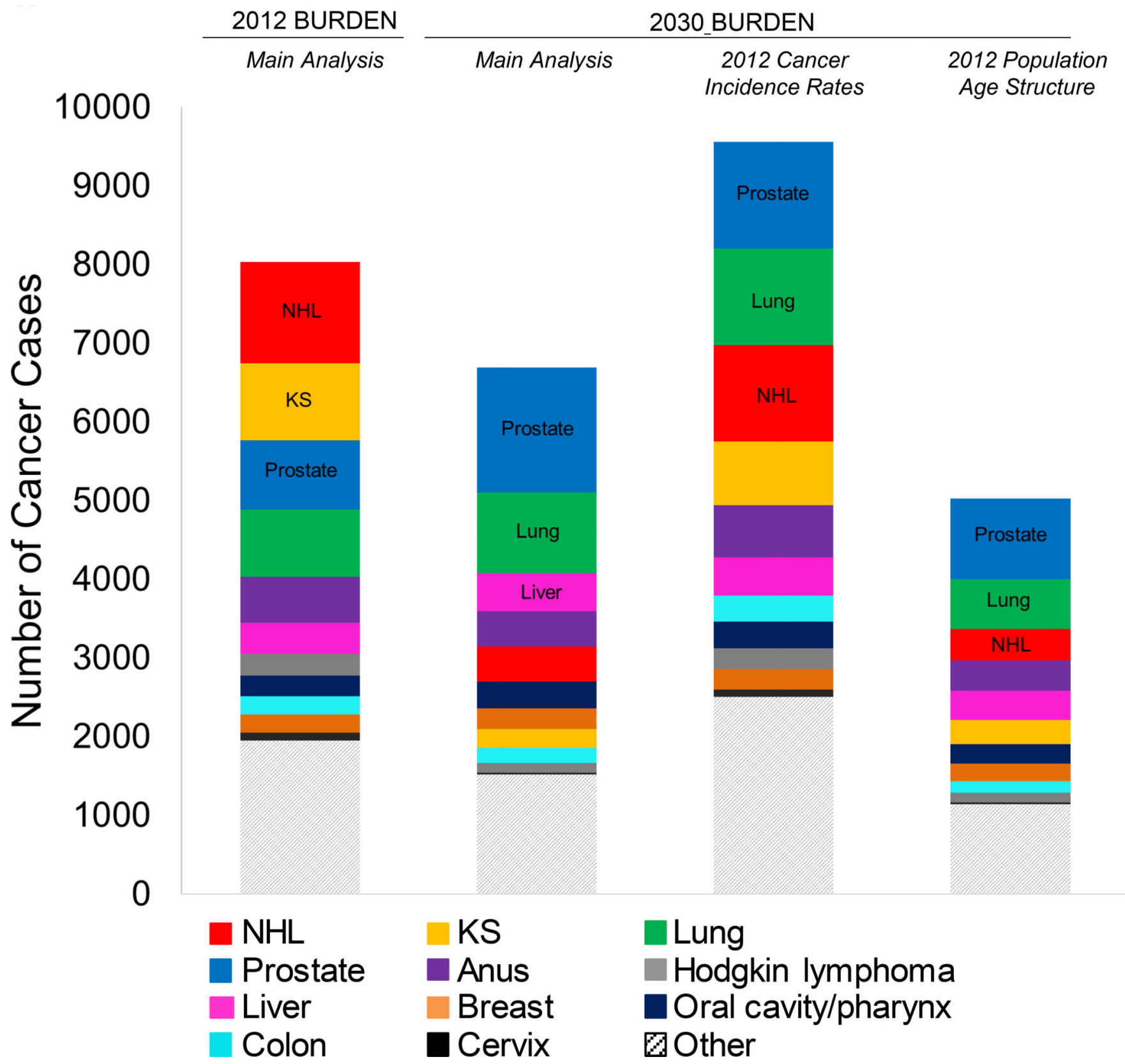

Figure 5. Estimated cancer burden (incident cancer diagnoses) among adults living with HIV in the United States, by cancer type, in 2012 and 2030.

Cancer burden estimates for 2030 were calculated 3 different ways: using the 2030 projected cancer incidence rates and 2030 projected age structure, using the 2012 modeled cancer incidence rates and 2030 projected age structure, and using the 2030 projected cancer incidence rates and 2012 modeled age structure. KS = Kaposi sarcoma; NHL = nonHodgkin lymphoma. 
Table.

Estimated Cancer Burden and Uncertainty Estimates in U.S. Adults With HIV During 2010, 2020, and 2030*

\begin{tabular}{lccc}
\multicolumn{1}{c}{ Cancer type } & \multicolumn{2}{c}{ Estimated Burden (Uncertainty Estimate) } \\
\cline { 2 - 4 } Total & $\mathbf{2 0 1 0}$ & $\mathbf{2 0 2 0}$ & $\mathbf{2 0 3 0}$ \\
AIDS-defining cancer & $8150(7280-9210)$ & $7490(5890-9490)$ & $6690(4950-9060)$ \\
Non-Hodgkin lymphoma & $2730(2440-3100)$ & $1340(990-1790)$ & $720(510-1070)$ \\
Kaposi sarcoma & $1490(1350-1660)$ & $750(590-940)$ & $450(360-580)$ \\
Cervical cancer & $1120(990-1290)$ & $540(370-770)$ & $240(130-450)$ \\
Non-AIDS-defining cancer & $5420(4850-6120)$ & $6150(4900-7700)$ & $5980(4430-7990)$ \\
Lung cancer & $830(750-920)$ & $910(850-950)$ & $1030(940-1090)$ \\
Prostate cancer & $750(680-840)$ & $1340(1060-1660)$ & $1590(1240-1820)$ \\
Anal cancer & $580(510-670)$ & $550(410-720)$ & $450(290-700)$ \\
Liver cancer & $360(300-430)$ & $460(360-590)$ & $480(360-630)$ \\
Hodgkin lymphoma & $300(260-350)$ & $200(140-270)$ & $120(70-200)$ \\
Oral cavity/pharyngeal cancer & $250(220-290)$ & $320(250-390)$ & $340(260-430)$ \\
Breast cancer & $220(190-270)$ & $260(210-330)$ & $260(200-330)$ \\
Colon cancer & $220(180-270)$ & $230(150-380)$ & $200(110-420)$ \\
Other & $1910(1760-2080)$ & $1880(1450-2410)$ & $1510(960-2380)$ \\
\hline
\end{tabular}

*ancer burden is defined as the number of incident cancer diagnoses. Results were rounded to the nearest 10 cases of cancer 